\title{
Earnings Transparency and Financial Analysts' Target Price Forecasts
}

\author{
Hyung Ju Park ${ }^{1} \&$ Joong-Seok Cho ${ }^{1}$ \\ ${ }^{1}$ School of Business Administration, Hanyang University, Seoul, South Korea \\ Correspondence: Joong-Seok Cho, School of Business Administration, Hanyang University, 222 Wangsimidoni-ro, \\ Seongdong-gu, Seoul 04763, South Korea. Tel: 82-2-2220-1078.
}

Received: January 14, 2020

Accepted: February 17, 2020

Online Published: June 28, 2020

doi:10.5430/ijfr.v11n4p1

URL: https://doi.org/10.5430/ijfr.v11n4p1

\begin{abstract}
This paper examines the effect of earnings transparency on analysts' target price forecast properties. The issuance of target price forecasts by financial analysts is a very recent event and target price forecasts are regarded as the most summarized and explicit estimate of the postulated future value of the firm.

The sample consists of financial analysts' forecasts of annual target price issued for firms listed on U.S. stock exchanges from 2001 to 2017. We measure each firm's earnings transparency as the contemporaneous co-movement between firm's earnings and change in earnings and stock returns, consisting in industry-specific and -neutral components in earnings-returns relation.

Our results show that target price forecasts for more transparent earnings are less biased and more tend to attain the actual stock prices. These results demonstrate that earnings transparency is positively related with analysts' target price forecasts. Our empirical results corroborate that more transparent accounting information help the market participants in forming more accurate and attainable forecasts. Our study extends the body of research studying the relation between analysts' forecast properties and the usefulness of accounting information by investigation target price forecasts.
\end{abstract}

Keywords: analysts' forecast, earnings transparency, target price

\section{Introduction}

We study the effect of earnings transparency on analysts' target price forecast properties. Target price forecasts are the most condensed and clear-cut prediction of the firm's postulated future value. Compared to other analysts' forecast products (i.e., annual (quarterly) earnings and cash flow forecasts and stock recommendations), the issuance of target price forecasts by financial analysts is a relatively recent event and studies on target price forecasts have steadily increased as their issuances of target price forecasts grow. However, research on target price forecasts has relatively unexplored and is few.

To investigate how earnings transparent are associated with the analysts' target forecast properties, we adopt earning transparency measure (TRANSPARENCY) operationalized by Barth, Konchitchki, and Landsman (2013). Stock returns indicate the degree of accounting (earnings) information explains firm value changes. As such, TRANSPARENCY is defined as the contemporaneous co-movement between firm's earnings and change in earnings and stock returns. In other words, it measures how much accounting (earnings) information explains firm value changes. TRANSPARENCY combines industry-specific and -neutral elements and higher TRANSPARENCY denotes more transparent earnings. As a result, as earnings are more transparent, they have higher explanatory power in describing firm value changes, inducing less information asymmetry.

Substantial empirical studies report that increased availability of relevant information decreases uncertainty and estimation risk and induces reduced information asymmetry (Barry \& Brown, 1985; Clarson, Guedes, \& Thompson, 1996). As more accounting information is explanatory, the extent of information asymmetry between management and investors dwindles and as a result, analysts' forecast difficulty decreases. Consequently, we posit that more transparent earnings represent less information asymmetry and transparent earnings affect analysts' forecast properties positively.

Our sample consists of financial analysts' forecasts of annual target price issued for firms listed on U.S. stock exchanges from 2001 to 2017. To be included in the sample, target price forecasts for each firm are required to be 
issued by at least two different analysts. And to allow analysts to reflect previous year's transparency information in their forecasts, we choose forecasts within the 60-day window after the prior year's earnings announcement date. As we hypothesize, we find earnings transparency positively affects analysts' target price forecasts. Specifically, target price forecasts issued for firms with more transparent earnings are less biased and these forecasts are more achievable, more likely to meet or to be above the actual stock prices, at the end of their forecast horizon.

\section{Literature Review}

Research on analysts' forecasts has studied the adequacy of financial analysts in understanding and incorporating pertinent information when they form their estimates. Stober (1992) and Abarbanell and Bushee (1997) finds that analysts are inefficient in correctly reflecting the necessary accounting information into their forecasts. Previous studies also report the existence of an optimistic bias in analysts' earnings estimates. Das, Levine, and Sivaramakrishnan (1998) and Lim (2001) show that analysts' earnings forecasts are more optimistic when analysts meet complexity in constructing their forecasts (i.e., when firms' earnings are less predictable). They conjecture that when information asymmetry is high, financial analysts' forecasts are more optimistically biased anticipating improving access to management, improving their forecast accuracy. Gu and Wu (2003) report that when analysts encounter skewed earnings, they intentionally bias their forecasts to lower their forecast errors and attain an information gain from management. In the study regarding analysts' job security, Hong and Kubik (2003) reveal that more optimistically biased forecast issuing analysts tend to be promoted and the analysts' turnover decisions are more related with optimism than with forecast accuracy.

Brav and Lehavy (2003) report an extensive market reaction to target price revisions and find that these target price forecast revisions provide incremental information even when they are accompanied by earnings forecasts and recommendation. Asquith, Mikhail, and Au (2005) also corroborate that of target price forecasts provide additional information in the existence of contemporaneously issued analysts' other forecasts. Da and Schaumburg (2011) and Bilinski, Lyssimachou, and Walker (2013) show analysts' target price forecast accuracy is positively associated with analysts' experience in a specialized industry and the size of brokerage issuing forecasts. Bradshaw, Lawrence, and Huang (2013) find financial analysts' tendency to overestimate their target price forecast and ineffective difference in sell-side analysts' forecasting abilities. Cho (2012 and 2013) reports that analysts do not properly digest implication of these information and this misunderstanding negatively affects their forecasts. Recently, Cheng, Su, Yan, and Zhao (2019) show that corporate governance structure positively affects target price forecast accuracy for Taiwanese firms.

These studies show that analysts do not correctly reflect relevant information such as accounting information in their forecasts. In addition, when they face difficulties in forming their forecast, they tend to be optimistically biased and these difficulties affect their forecasts negatively.

\section{Sample and Research Design}

\subsection{Sample}

Initially, we identify annual target price forecasts issued for firms listed on U.S. stock exchanges from the I/B/E/S's detailed (split-adjusted) price target file for the period 2001-2017. We select all annual target price forecasts issued within the subsequent 60-day window after the prior year's earnings announcement date. The 60-day window is used to reflect the effect of the previous year's transparency information in analysts' target price forecast issuances and to avoid the compounding effect from the following quarterly earnings announcement. Then, we restrict our sample to those firms with forecasts issued by at least two distinct financial analysts. If multiple forecasts are issued by an identical individual analyst in the 60-day window period, we choose the most recent one.

Using the COMPUSTAT database, we collect firm-related financial statement data. To lessen the influence of outliers, we delete observations with total assets and sales less than US\$10 million or share price less than $\$ 1$. To eliminate the improperly aligned stock split factors, we also remove the observations whose target price/closing share price ratios are at the bottom 1st percent or greater than 2 . For earnings transparency measure, monthly return data are drawn from the CRSP Monthly Stock file. To alleviate undue effect of outliers, we restrict our earnings variables,

$\frac{E_{t}}{P_{t-1}}, \frac{E_{t-1 t}}{P_{t-1}}$, and $\frac{\Delta E_{t}}{P_{t-1}}$ between -1.5 and +1.5 and truncate annual return (RET) at top and bottom 1 percent, where $E_{t}$ represents income before extraordinary items and discontinued operations at year $\mathrm{t}, P_{t-1}$ closing share price at the prior year, and RET annual return measured beginning three months after the firm's fiscal year (Easton and Harris, 
1991).

We delete firm-years observation with negative book or without necessary data for control variables. In addition, we winsorize all variables except indicator variables at the 1 and 99 percent. Our final sample obtain 13,713 firm-year observations from fiscal year 2001 to 2017. Our sample expands at the early sample period and then is stable over the remaining period.

Table 1. Sample distribution

\begin{tabular}{|c|c|c|}
\hline Year & Number of Firms & Percent \\
\hline 2001 & 448 & 3.27 \\
\hline 2002 & 719 & 5.24 \\
\hline 2003 & 716 & 5.22 \\
\hline 2004 & 817 & 5.96 \\
\hline 2005 & 810 & 5.91 \\
\hline 2006 & 795 & 5.80 \\
\hline 2007 & 803 & 5.86 \\
\hline 2008 & 806 & 5.88 \\
\hline 2009 & 837 & 6.10 \\
\hline 2010 & 842 & 6.14 \\
\hline 2011 & 888 & 6.48 \\
\hline 2012 & 871 & 6.35 \\
\hline 2013 & 875 & 6.38 \\
\hline 2014 & 874 & 6.37 \\
\hline 2015 & 867 & 6.32 \\
\hline 2016 & 884 & 6.45 \\
\hline 2017 & 861 & 6.27 \\
\hline Total & 13,713 & 100.00 \\
\hline
\end{tabular}

\subsection{Earning Transparency}

Adopting the methodology developed in Barth et al. (2013), each firm's earnings transparency is measured as follows. TRANSPARENCY is constructed as the contemporaneous co-movement between firm's earnings and change in earnings and stock returns. The measuring process is a two-step procedure. First, we calculate the explanatory powers from industry-specific and industry-neutral annual earnings-returns regressions, respectively. Then, we add these two $R^{2} \mathrm{~s}$ as earnings transparency measure. Specifically, as a first step, we estimate industry-specific earnings-returns co-movement. For the industry classifications, we use the industry definition in Barth, Beaver, and Landsman (1998). For each industry with at least 10 observations, we estimate the following industry-specific ordinary least squares (OLS) regression of firm returns on earnings and change in earnings:

$$
\operatorname{RET}_{I, j, t}=\alpha+\alpha_{1} * \frac{E_{I, j t}}{P_{I, j, t-1}}+\alpha_{2} * \frac{\Delta E_{I, i, t}}{P_{I, j, t-1}}+* \epsilon_{i, t}
$$

where $\mathrm{j}$ indicates individual firm, $\mathrm{I}$ industry where firm $\mathrm{j}$ belongs, and $\mathrm{t}$ fiscal year. We take $R^{2}$ from the first-regression which is estimating the industry-specific co-movement relation. By its construction, each firm in the same industry has the same $R^{2}$ for each year and this component shows the industry-specific explanatory power.

The next $R^{2}$ is taken from the second regression, which is industry-neutral. First, we split firms into four clusters for each year based on the residual values from the first equation and run the second regression for each of the residual-value quartile groups to get its $R^{2}$. The second regression implies the extent of earnings-returns relation 
which cannot be accounted for by industry-membership. So, it can be said that $R^{2}$ from the second regression is each firm's industry-neutral portion in its earnings-returns relation.

$$
R E T_{Q, t}=\beta+\beta_{1} * \frac{E_{Q, j, t}}{P_{Q, j, t-1}}+\beta_{2} * \frac{\Delta E_{Q, j, t}}{P_{Q, j, t-1}}+* \epsilon_{P, t}
$$

where $\mathrm{Q}$ indicates residual value quartile.

TRANSPARENCY is defined as the sum of two $R^{2} s$ from equation (1) and (2). Therefore, TRANSPARENCY consists of industry-specific and -neutral components in earnings-returns relation (Note 1). Higher TRANSPARENCY indicates more transparent earnings and more transparent earnings represent less information asymmetry. Therefore, we expect that earnings transparency affects positively financial analysts' target price forecasts.

\subsection{Target Price Forecasts}

We use two measures, $B I A S$ and $M B E$, to gauge analysts' target price forecast performance. To measure the extent of optimism in analysts' forecasts, we calculate $B I A S$, the signed continuous value of $(A P-M T F) / C P$, where $A P$ and $C P$ are the share price at the end of the forecast horizon and at the previous year's earnings announcement date, respectively. MTF is the mean value of target price forecasts issued within 60-day window interval after the prior year's earnings announcement date and reflects the prior year's earnings information as the target price forecast consensus measure. By construction, higher value of BIAS indicates more positive optimism in the analysts' annual target price estimates. Previous studies show that analysts' forecasts are more optimistically issued when analysts face complexity in constructing predictions (Das et al., 1998; Lim, 2001). Therefore, we expect that more transparent earnings induces less positive optimism in forming target price forecasts. $M B E$ indicates the attainability of the analysts' annual target price forecasts specifying whether analysts' forecasts beat or meet the actual stock price at the end of the forecast period. If $M T F$ is attained, $M B E$ is set to 1 and 0 otherwise. We anticipate target price forecasts for firms with more transparent accounting informaton to be more achievable because transparent earnings are more explanatory and reduce information asymmetry. Therefore, we expect the positive effect of TRANSPARENCY on $M B E$.

\subsection{Model Specification}

To examine the effect of earnings transparency on analysts' target price forecast properties, we run a series of multiple regression analyses. Our multivariate examinations are based on the following OLS and logistic regressions. These models are developed reflecting the extant literature. To circumvent potential heteroscedasticity and correlation, we compose two-way-clustered standard errors by firm and year and report results based on them (Gow, Ormazabal, \& Taylor, 2010):

$$
\begin{aligned}
\text { TPFP }_{i, t} & =\gamma+\gamma_{1} \text { TRANSPARENCY }_{i, t-1}+\gamma_{2} \text { PRET }_{i, t-1}+\gamma_{3} \text { PSTD }_{i, t-1}+\gamma_{4} \text { BM }_{i, t} \\
& +\gamma_{5} L_{\text {LEV }}{ }_{i, t}+\gamma_{6} \text { LOSS }_{i, t}+\gamma_{7} \text { SIZE }_{i, t}+\varepsilon_{i, t}
\end{aligned}
$$

To measure the analysts' target price forecast performance (TPFP), we use two dependent variables, BIAS and $M B E$. The first main dependent variable, $B I A S$, a continuous variable, gauges the degree of positive optimism in the analysts' annual target price forecast consensus. An indictor variable, $M B E$ denotes whether the consensus of target price forecasts issued is attained, either beats or meets the actual stock price, at the end of the forecast horizon.

We lag TRANSPARENCY to mirror the fact that analysts form their forecasts after they have observed specific firms' operation in year $t-1$. We expect that as firms' earnings are more transparent, financial analysts can interpret and reflect information on firms more easily in forming their forecasts. So, we posit that TRANSPARENCY has a positive effect on analysts' target price forecast accuracy and reduces their bias.

We control for variables that have been known to influence analysts' forecasts. To control for price momentum, we include PRET, which is the six-month buy-and-hold stock return before the target price release month and add the past stock price volatility measure (PSTD), the standard deviation of daily closing prices over the one-year period prior to the target price release month. $B M$ is the ratio of book value of equity to the market value of equity, controlling for firm fundamentals such as growth. $L E V$ is added to reflect financial distress. $L E V$ is measured as the ratio of long-term liabilities to total assets. Previous research finds that analysts' forecasts for loss years tend to be more positively biased and less accurate (e.g., Lang \& Lundholm, 1996; Brown, 2001; Duru \& Reeb, 2002). To capture the forecast complexity and firm performance, we add LOSS, a dummy with one for negative operating results and zero for otherwise. Lastly, we control for size effect and any potential omitted variables using the natural logarithm of value of market capitalization (SIZE). All variables other than earnings transparency variable are measured at year $t$. 


\section{Empirical Results}

\subsection{Univariate Statistics}

Table 2 provides descriptive statistics for the variables used in our study. For our sample firm-year observations, the average (median) of 5.7164 (4.0000) target price forecasts are issued. The mean value of target price is around $6.99 \%$ higher than the closing stock price at the preceding year's earnings announcement $(M T F / C P=1.0699)$ and its median value is $11.21 \%$ higher. The mean (median) value of earnings transparency measure, TRANSPARENCY, is 0.3768 (0.3567). This indicates that earnings and change in earnings together explain around $38 \%$ of contemporaneous returns, combining industry-specific and -neural components. TRANSPARENCY's quartile values range at the 1st quartile of 0.2460 and the 3 rd quartile of 0.4975 . Our earnings transparency measure shows considerable variation. On average $48.03 \%$ of firm-year observations beat or meat their target price forecasts $(M B E=0.4803)$. The median value of BIAS is 0.0148 , indicating modest optimism in their forecasts.

Table 2. Descriptive statistics $(\mathrm{n}=13,713)$

\begin{tabular}{llllll}
\hline Variable & Mean & Std. dev & Q1 & Q2 & Q3 \\
\hline TPS issued/firm & 5.7164 & 4.1753 & 3.0000 & 4.000 & 7.000 \\
\hline MTF/CP & 1.0699 & 0.2968 & 0.9706 & 1.1121 & 1.2346 \\
\hline TRANSPARENCY & 0.3768 & 0.1749 & 0.2460 & 0.3567 & 0.4975 \\
\hline$M B E$ & 0.4803 & 0.4996 & 0.0000 & 0.0000 & 1.000 \\
\hline$B I A S$ & 0.0199 & 0.4444 & -0.2349 & 0.0148 & 0.2508 \\
\hline$P R E T$ & 0.0652 & 0.2494 & -0.0694 & 0.0648 & 0.2003 \\
\hline PSTD & 4.5422 & 4.1565 & 1.9597 & 3.3119 & 5.6307 \\
\hline$B M$ & 0.3397 & 0.4834 & 0.0533 & 0.1654 & 0.4101 \\
\hline LEV & 0.1724 & 0.1617 & 0.0214 & 0.1431 & 0.2752 \\
\hline LOSS & 0.1486 & 0.3556 & 0.0000 & 0.0000 & 0.0000 \\
\hline SIZE & 7.7811 & 1.5859 & 6.6553 & 7.7009 & 8.8212 \\
\hline
\end{tabular}

Variable definitions:

$T P$ : 12-month-ahead target price forecast.

$M T F$ : mean value of $T P$.

$C P$ : closing share price at the prior year's earnings announcement date.

$A P$ : actual share price at the end of the forecast horizon.

TRANSPARENCY: contemporaneous co-movement between firm's earnings and change in earnings and stock returns. First, we run the industry-specific regression to estimate industry-specific earnings-returns co-movement to get industry-specific $R^{2}$ :

$$
\operatorname{RET}_{I, j, t}=\alpha+\alpha_{1} * \frac{E_{I, j t}}{P_{I, j, t-1}}+\alpha_{2} * \frac{\Delta E_{I, i, t}}{P_{I, j, t-1}}+* \epsilon_{i, t}
$$

where $\mathrm{j}$ indicates individual firm, $\mathrm{I}$ industry where firm $\mathrm{j}$ belongs, and $\mathrm{t}$ fiscal year. $E_{t}$ represents income before extraordinary items and discontinued operations at year $\mathrm{t}, P_{t-1}$ closing share price at the prior year, and RET annual return measured beginning three months after the firm's fiscal year. Then, we split firms into four clusters for each year based on the residual values from the first equation and run the second regression for each of the residual-value quartile groups to figure out each firm's industry-neutral portion in its earnings-returns relation:

$$
R E T_{Q, t}=\beta+\beta_{1} * \frac{E_{Q, j, t}}{P_{Q, j, t-1}}+\beta_{2} * \frac{\Delta E_{Q, j, t}}{P_{Q, j, t-1}}+* \epsilon_{P, t}
$$

where Q indicates residual value quartile. TRANSPARENCY is defined as the sum of two $R^{2} s$ from equation (1) and 
(2).

$B I A S$ : signed continuous value of $(A P-M T F) / C P$.

$M B E=1$ if $A P$ is attained at the end of the forecast period and equals 0 otherwise.

PRET: six-month buy-and-hold raw return excluding dividends prior to the target price release month.

PSTD: standard deviation of daily closing prices over the one-year period ending prior to the target price release month.

$B M$ : ratio of book value of equity to the market value of equity.

$L E V$ : ratio of long-term liabilities to total assets.

LOSS: 1 for negative operating results and 0 for otherwise.

SIZE: natural log value of price per share multiplied by the number of shares outstanding.

Table 3 reports Spearman correlation coefficients. As we hypothesize, TRANSPARENCY is negatively correlated with BIAS (-0.1172, p-value $<0.0001)$ and positively with $M B E(0.0988$, p-value $<0.0001)$. Even though related variables are not controlled for, these results show that as more transparent firms' earnings are, analysts' target price forecasts are less biased and more attainable.

Prior research shows that the quality of firm accounting information and the level of information asymmetry is negatively related. We investigate the correlation between the bid-ask spread (SPREAD) before target price forecasts are announced and TRANSPARENCY. SPREAD is a commonly used information asymmetry measure. To construct $S P R E A D$, we calculate the median daily closing bid-ask spread, which is scaled by the average of closing bid and ask prices over one-year period before the year $t-1$ earnings announcement date.. TRANSPARENCY measures firm earnings' explanatory power in depicting firm value changes. We anticipate that more transparent accounting earnings reduce uncertainty about the value of the firm and therefore, are coupled with less information asymmetry. As we posit, our untabulated results show a highly negative correlation between TRANSPARENCY and SPREAD $(-0.0256$ at the 1 percent level).

These simple correlations demonstrate that transparent earnings positively affect analysts' target price forecasts and as more transparent earnings are, target price forecasts are more attainable and less positively biased. The correlation results corroborate our projections.

Table 3. Spearman correlation matrix $(\mathrm{n}=13,713)$

\begin{tabular}{lllllllll}
\hline & MBE & BIAS & PRET & PSTD & BM & LEV & LOSS & SIZE \\
\hline TRANSAPRENCY & $0.0988^{* * *}$ & $-0.1172^{* * *}$ & $0.0698^{* * *}$ & $-0.0650^{* * *}$ & $-0.0279^{* * *}$ & $0.0382^{* * *}$ & -0.0039 & $0.0371^{* * *}$ \\
\hline MBE & & $-0.8654^{* * *}$ & $0.3037^{* * *}$ & $0.1863^{* * *}$ & $0.0684^{* * *}$ & -0.0116 & $-0.1713^{* * *}$ & $0.1702^{* * *}$ \\
\hline BIAS & & $-0.3657^{* * *}$ & $-0.1618^{* * *}$ & $-0.0866^{* * *}$ & $0.0218^{* * *}$ & $0.2362^{* * *}$ & $-0.2222^{* * *}$ \\
\hline PRET & & & -0.0053 & $0.0244^{* * *}$ & -0.0110 & $-0.0689^{* * *}$ & $0.0717 * * *$ \\
\hline PSTD & & & $0.1566^{* * *}$ & $0.0763^{* * *}$ & $-0.1349^{* * *}$ & $0.3517 * * *$ \\
\hline BM & & & & $-0.1332^{* * *}$ & $-0.1225^{* * *}$ & $-0.5072^{* * *}$ \\
\hline LEV & & & & & $0.0452^{* * *}$ & $0.2165^{* * *}$ \\
\hline LOSS & & & & & & $-0.2622^{* * *}$ \\
\hline
\end{tabular}

$*, * *$, and $* * *$ indicate statistical significance at the 10,5 , and $1 \%$ level, respectively.

All variables are defined in Table 2 .

\subsection{Regression Analysis}

Table 4 reveals the results of our multiple regression. We regress the measures of the analysts' target price forecast attainability and bias on firm earning transparency. All results are reported using the clustered robust standard errors to accommodate fixed effects of both firm and year with a two-tailed test.

Model 1 shows our first regression results. We examine the relation between TRANSPARENCY and BIAS, the signed 
continuous value estimating the degree of positive optimism in the analysts' target price forecasts. Prior studies show that when information asymmetry is high, analysts incline to publish more optimistically biased earnings forecasts. We anticipate more transparent earnings reduce this bias and the coefficient on TRANSPARENCY is negative. The coefficient of TRANSPARENCY is -0.2504 , negative and significant at the 5 percent level. These are consistent with univariate correlation analysis indicating that target price forecasts for firms with more transparent accounting information are less positively biased.

In the second model, our dependent variable is $M B E$, an indicator variable and as a result, we use the logistic regression. We hypothesize that more transparent earnings ease uncertainty in estimating the value of the firm due to the reduced information asymmetry. Therefore, earnings transparency positively affects analysts target price forecasts and the forecasts for more transparent firms are more attainable. As we expected, the coefficient of TRANSPARENCY is 1.1827 and statistically significant at the 1 percent level. These results indicate that transparent earnings are more informative and positively affect target price forecasts increasing the probability to attain analysts' target price forecasts. Control variables are mostly congruous with our expectations. Size (SIZE) and momentum (PRET) are positively associated with target price forecasts and leverage (LEV) and loss (LOSS) are negatively.

Combined, our results suggest that analysts' target price forecasts issued for firms with more transparent earnings are less positively biased and more attainable at the end of the forecast period. The empirical evidence demonstrates that earnings transparency positively affects analysts' target price forecast properties.

Table 4. Multivariate regression analysis $(n=13,713)$

\begin{tabular}{lllll}
\hline & $(1)$ & & \\
& & & \\
& & & \\
& & & \\
& & & \\
Variable & Coefficient & t-stat & Coefficient & z-stat \\
\hline Intercept & 0.4816 & $5.17 * * *$ & -2.2792 & $-6.31 * * *$ \\
\hline TRANSPARENCY & -0.2504 & $-2.32 * *$ & 1.1827 & $2.58 * * *$ \\
\hline PRET & -0.6109 & $-7.69 * * *$ & 2.6384 & $6.43 * * *$ \\
\hline PSTD & -0.0064 & -1.23 & 0.0533 & $2.69 * * *$ \\
\hline BM & -0.0937 & $-2.71 * * *$ & 0.3692 & $3.04 * * *$ \\
\hline LEV & 0.1178 & $2.98 * * *$ & -0.5619 & $-2.88 * * *$ \\
\hline LOSS & 0.1685 & $4.62 * * *$ & -0.7699 & $-5.43 * * *$ \\
\hline SIZE & -0.0452 & $-3.97 * * *$ & 0.1795 & $4.53 * * *$ \\
\hline Adj. or Pseudo $\mathrm{R}^{2}$ & 0.2134 & & 0.1110 & \\
\hline
\end{tabular}

$*, * *$, and $* * *$ indicate statistical significance at the 10,5 , and $1 \%$ level, respectively.

All variables are defined in Table 2.

\section{Conclusions}

This paper examines the effect of earnings transparency on analysts' target price forecast properties. Target price forecasts are regarded as the most summarized and explicit estimate of the postulated future value of the firm. The issuance of target price forecasts by financial analysts is a recent event and analysts have steadily. However, research on target price forecasts has relatively unexplored and is few.

Our sample consists of financial analysts' forecasts of annual target price issued for firms listed on U.S. stock exchanges from 2001 to 2017 . To be included in the sample, target price forecasts for each firm are required to be issued by at least two different analysts. And to allow analysts to reflect previous year's transparency information in their forecasts and, we choose forecasts within the 60-day window after the previous year's earnings announcement date.

Based on the methodology outlined in Barth et al. (2013), we measure each firm's earnings transparency. TRANSPARENCY is constructed as the contemporaneous co-movement between firm's earnings and change in earnings and stock returns. As a two-step procedure, first, we calculate the explanatory powers from industry-specific 
and industry-neutral annual earnings-returns regressions, respectively. Then, we add these two $R^{2} \mathrm{~s}$ as earnings transparency measure. By construction, TRANSPARENCY consists of industry-specific and -neutral components in earnings-returns relation. Higher TRANSPARENCY indicates more transparent earnings and more transparent earnings represent less information asymmetry. Therefore, we expect that earnings transparency affects positively financial analysts' target price forecasts properties.

Consistent with our predictions, our results show that target price forecasts for more transparent earnings are less biased when they are issued and more attainable at the end of the forecast period. These empirical results demonstrate that earnings transparency positively influences analysts' target price forecasts. Our results verify that the increased availability of relevant information decreases uncertainty and estimation risk and the extent of information asymmetry between management and investors. These results demonstrate that more transparent earnings are positively associated with analysts' target price forecasts properties and as more transparent earnings are, target price forecasts are more attainable and less positively biased. The correlation results corroborate our projections.

Our study extends the body of research studying the association between the usefulness of accounting information and analysts' forecasting accuracy by investigation target price forecasts. Our empirical results are consistent with the fact that more transparent accounting information helps the market participants in forming more accurate and attainable forecasts. However, we acknowledge that our study has limitations such as indirect earning transparency measure, which is essentially is exploratory and the need for a further articulation.

\section{References}

Abarbanell, J. S., \& Bushee, B. J. (1997). Fundamental Analysis, Future Earnings, and Stock Prices. Journal of Accounting Research, 35, 1-24. https://doi.org/10.2307/2491464

Asquith, P., Mikhail, M., \& Au, A. (2005). Information content of equity analyst reports. Journal of Financial Economics, 75, 245-282. https://doi.org/10.1016/j.jfineco.2004.01.002

Barry, C. B., \& Brown, S. J. (1985). Differential information and security market equilibrium. Journal of Financial and Quantitative Analysis, 20(4), 407-422. https://doi.org/10.2307/2330758

Barth, M. E., Beaver, W. H., \& Landsman, W. R. (1998). Relative valuation roles of equity book value and net income as a function of financial health. Journal of Accounting and Economics, 25(1), 1-34. https://doi.org/10.1016/S0165-4101(98)00017-2

Barth, M. E., Konchitchki, Y., \& Landsman, W. R. (2013). Cost of capital and earnings transparency. Journal of Accounting and Economics, 55(2-3), 206-224. https://doi.org/10.1016/j.jacceco.2013.01.004

Bilinski, P., Lyssimachou, D., \& Walker, M. (2013). Target price accuracy: International evidence. The Accounting Review, 88(3), 825-851. https://doi.org/10.2308/accr-50378

Bradshaw, M. T., Lawrence, D. B., \& Huang, K. (2013). Do sell-side analysts exhibit differential target price forecasting ability?. Review of Accounting Studies, 18(4), 930-955. https://doi.org/10.1007/s11142-012-9216-5

Brav, A., \& Lehavy, R. (2003). An empirical analysis of analysts' target prices: short-term informativeness and long-term dynamics. Journal of Finance, 58, 1933-1968. https://doi.org/10.1111/1540-6261.00593

Brown, L. D. (2001). A Temporal Analysis of Earnings Surprises: Profits versus Losses. Journal of Accounting Research, 39(2), 221-241. https://doi.org/10.1111/1475-679X.00010

Cheng, L. Y., Su, Y. C., Yan, Z., \& Zhao, Y. (2019). Corporate governance and target price accuracy. International Review of Financial Analysis, 64, 93-101. https://doi.org/10.1016/j.irfa.2019.05.005

Cho, J. (2012). The effect of accruals on security analysts' target price forecast performance. Journal of Applied Economic Sciences, 7(3), 228-234.

Cho, J. (2013). The relation between accounting quality and security analysts' target price forecast performance. Actual Problems of Economics, 141, 503-510

Clarkson, P., Guedes, J., \& Thompson, R. (1996). On the diversification, observability, and measurement of estimation risk. Journal of Financial and Quantitative Analysis, 31(1), 69-84. https://doi.org/10.2307/2331387

Da, Z., \& Schaumburg, E. (2011). Relative valuation and analyst target price forecasts. Journal of Financial Markets, 14(1), 161-192. https://doi.org/10.1016/j.finmar.2010.09.001

Das, S., Levine, C., \& Sivaramakrishnan, K. (1998). Predictability and Bias in Analysts? Earnings Forecasts. The Accounting Review, 73(2), 277-294. 
Duru, A., \& Reeb, D. M. (2002). International Diversification and Analysts' Forecast Accuracy and Bias. The Accounting Review, 77(2), 415-433. https://doi.org/10.2308/accr.2002.77.2.415

Gow, I., Ormazabal, G., \& Taylor, D. (2010). Correcting for cross-sectional and time-series dependence in accounting research. The Accounting Review, 85, 483-512. https://doi.org/10.2308/accr.2010.85.2.483

$\mathrm{Gu}, \mathrm{Z}$., \& Wu, J. S. (2003). Earnings skewness and analyst forecast bias. Journal of Accounting and Economics, 35(1), 5-29. https://doi.org/10.1016/S0165-4101(02)00095-2

Hong, H., \& Kubik, J. D. (2003). Analyzing the analysts: Career concerns and biased earnings forecasts. The Journal of Finance, 58(1), 313-351. https://doi.org/10.1111/1540-6261.00526

Lang, M. H., \& Lundholm, R. J. (1996). Corporate Disclosure Policy and Analyst Behavior. The Accounting Review, 71(4), 467-492.

Lim, T. (2001). Rationality and analysts' forecast bias. The Journal of Finance, 56(1), 369-385. https://doi.org/10.1111/0022-1082.00329

Stober, T. L. (1992). Summary Financial Statement Measures and Analyst Forecast of Earnings. Journal of Accounting and Economics, 15, 347-372. https://doi.org/10.1016/0165-4101(92)90024-V

\section{Note}

Note 1. Barth et al. (2013) test and show the validity of TRANSPARENCY using AIMR disclosure scores and S\&P Ranking indices. In construction of TRANSPARENCY, they test the different classifications of residual values and their results are unaffected by the different classification scheme. 